\title{
Urinary diversion after radical cystectomy for bladder cancer: options, patient selection, and outcomes
}

\author{
Richard K. Lee', Hassan Abol-Enein ${ }^{6}$, Walter Artibani', Bernard Bochner², \\ Guido Dalbagni ${ }^{2}$, Siamak Daneshmand ${ }^{3}$, Yves Fradet ${ }^{9}$, Richard E. Hautmann ${ }^{10}$, \\ Cheryl T. Lee ${ }^{4}$, Seth P. Lerner ${ }^{5}$, Armin Pycha ${ }^{8}$, Karl-Dietrich Sievert ${ }^{11}$, Arnulf Stenz ${ }^{11}$, \\ Georg Thalmann ${ }^{12}$ and Shahrokh F. Shariat ${ }^{1,13}$
}

\begin{abstract}
'James Buchanan Brady Foundation, Department of Urology and Division of Medical Oncology, Weill Cornell Medical College, New York-Presbyterian Hospital, ${ }^{2}$ Urology Service, Department of Surgery, Memorial Sloan Kettering Cancer Center, New York, NY, ${ }^{3}$ Keck School of Medicine, USC, University of Southern California (USC) Institute of Urology, Los Angeles, CA, ${ }^{4}$ Department of Urology, University of Michigan, Ann Arbor, MI, ${ }^{5}$ Department of Urology, Baylor College of Medicine, Houston, TX, USA, ${ }^{6}$ Department of Urology, Mansoura University, Mansoura, Egypt, ${ }^{7}$ Department of Urology, Verona University, Verona, ${ }^{8}$ Department of Pathology, Central Hospital of Bolzano, Bolzano, Italy, ${ }^{9}$ Urology Service, Department of Surgery, Laval University, Quebec City, Quebec, Canada, ${ }^{10}$ Department of Urology, University of Ulm, Ulm, "Department of Urology, Universitätsklinikum Tübingen, Tübingen, Germany, ${ }^{12}$ Department of Urology, Inselspital, Bern, Switzerland, and ${ }^{13}$ Department of Urology, Medical University of Vienna, Vienna, Austria
\end{abstract}

Extra-institutional Funding: None.

\section{Context}

- The urinary reconstructive options available after radical cystectomy (RC) for bladder cancer are discussed, as are the criteria for selection of the most appropriate diversion, and the outcomes and complications associated with different diversion options.

\section{Objective}

- To critically review the peer-reviewed literature on the function and oncological outcomes, complications, and factors influencing choice of procedure with urinary diversion after RC for bladder carcinoma.

\section{Evidence Acquisition}

- A Medline search was conducted to identify original articles, review articles, and editorials on urinary diversion in patients treated with RC. Searches were limited to the English language.

- Keywords included: 'bladder cancer', 'cystectomy', 'diversion', 'neobladder', and 'conduit'.

- The articles with the highest level of evidence were selected and reviewed, with the consensus of all of the authors of this paper.

\section{Evidence Synthesis}

- Both continent and incontinent diversions are available for urinary reconstruction after RC. In appropriately selected patients, an orthotopic neobladder permits the elimination of an external stoma and preservation of body image without compromising cancer control. However, the patient must be fully educated and committed to the labour-intensive rehabilitation process. He must also be able to perform self-catheterisation if necessary.

- When involvement of the urinary outflow tract by tumour prevents the use of an orthotopic neobladder, a continent cutaneous reservoir may still offer the opportunity for continence albeit one that requires obligate self-catheterisation.

- For patients who are not candidates for continent diversion, the ileal loop remains an acceptable and reliable option.

\section{Conclusions}

- Both continent and incontinent diversions are available for urinary reconstruction after RC.

- Orthotopic neobladders optimally preserve body image, while continent cutaneous diversions represent a reasonable alternative.

- Ileal conduits represent the fastest, easiest, least complication-prone, and most commonly performed urinary diversion.

\section{Keywords}

bladder cancer, outcome assessment (health care), patient selection, radical cystectomy, urinary bladder neoplasms, urinary diversion 


\section{Introduction}

Radical cystectomy (RC) for bladder cancer requires reconstruction of the lower urinary tract. Ureterosigmoidostomy was the first widely used surgical technique for urinary diversion, providing an effective diversion using the anal sphincter for continence. However, deterioration of renal function over time, metabolic complications, and the increased risk for secondary malignancies limited its usefulness as a urinary diversion.

Subsequent surgical advances have led to major improvements in both functional outcomes and health-related quality of life (HRQOL). We discuss the available reconstructive options after $\mathrm{RC}$ for bladder cancer, criteria for selection, and the outcomes associated with each option.

\section{Evidence Acquisition}

A Medline search was conducted to identify original English language articles on urinary diversion after RC using the keywords 'bladder cancer,' 'cystectomy', 'diversion',

'neobladder', and 'conduit'. In all, 105 articles were identified and those with the highest level of evidence were selected and reviewed. Reviews and other secondary data sources were excluded.

\section{Evidence Synthesis}

Depending on the segment of bowel used to create a urinary diversion, specific metabolic consequences may ensue, as outlined in Table 1. Postoperative bowel function may also be altered. The ideal urinary diversion has yet to be developed (Table 2). Currently, urinary reconstruction falls into two general categories: incontinent diversions, such as the ileal conduit, and continent diversions, including both cutaneous reservoirs and orthotopic reservoirs connected to the urethra.

\section{Ureterosigmoidostomy}

One of the first urinary diversions using bowel included the use of ureterosigmoidostomy, where the ureters were anastomosed to the sigmoid. Its major advantage is the potential for spontaneous emptying of urine with stool, i.e. continence is maintained by the anal sphincter.

Table 1 Primary indications and metabolic consequences for use of bowel segments.

\begin{tabular}{|c|c|c|c|}
\hline Bowel segment & Primary indication & Metabolic consequences & Clinical symptoms \\
\hline Gastric & $\begin{array}{l}\text { - Children requiring diversion (exstrophy, pelvic } \\
\text { radiation) } \\
\text { - Renal insufficiency }\end{array}$ & $\begin{array}{l}\text { Metabolic alkalosis ( } \downarrow \text { K and } \mathrm{Cl} \text {, } \\
\text { hypergastrinaemia) }\end{array}$ & $\begin{array}{l}\text { - Haematuria-dysuria syndrome } \\
\text { - Dehydration, lethargy, seizures, respiratory } \\
\text { distress }\end{array}$ \\
\hline Jejunum & $\begin{array}{l}\text { - Pelvic radiation } \\
\text { - Deficient ureteric length } \\
\text { - Compromised viability of other small or large } \\
\text { bowel }\end{array}$ & $\begin{array}{l}\text { Metabolic acidosis ( } \downarrow \text { Na and } \mathrm{Cl}, \uparrow \mathrm{K} \text {, } \\
\text { azotaemia) }\end{array}$ & $\begin{array}{l}\text { Dehydration, nausea/vomiting, weakness, } \\
\text { lethargy, seizures }\end{array}$ \\
\hline Ileum or ileal-colic reservoirs & $\begin{array}{l}\text { - Malignancies requiring removal of the bladder } \\
\text { - Severe haemorrhagic cystitis } \\
\text { - Incontinence }\end{array}$ & $\begin{array}{l}\text { Metabolic acidosis ( } \uparrow \mathrm{Cl}, \downarrow \text { bicarbonate, } \\
\text { azotaemia) }\end{array}$ & $\begin{array}{l}\text { - Fatigue, anorexia, weight loss, diarrhoea, } \\
\text { polydipsia } \\
\text { - } \mathrm{B}_{12} \text { and fat-soluble vitamin deficiency } \\
\text { - Diarrhoea, urinary calculi, cholelithiasis }\end{array}$ \\
\hline Colon (ureterosigmoidostomy) & $\begin{array}{l}\text { - Children requiring diversion (extrophy, pelvic } \\
\text { radiation) } \\
\text { - No other bowel segment alternative }\end{array}$ & $\begin{array}{l}\text { Metabolic acidosis ( } \uparrow \mathrm{Cl}, \downarrow \text { bicarbonate, } \\
\text { azotaemia) }\end{array}$ & $\begin{array}{l}\text { - Fatigue, anorexia, weight loss, diarrhoea, } \\
\text { polydipsia } \\
\text { - Pyelonephritis } \\
\text { - Adenocarcinoma at anastomotic site }\end{array}$ \\
\hline Transverse colon conduit & $\begin{array}{l}\text { - Malignancies requiring removal of the bladder } \\
\text { - Small bowel not practical }\end{array}$ & $\begin{array}{l}\text { Metabolic acidosis ( } \uparrow \mathrm{Cl}, \downarrow \text { bicarbonate, } \\
\text { azotaemia) }\end{array}$ & $\begin{array}{l}\text { - Fatigue, anorexia, weight loss, diarrhoea, } \\
\text { polydipsia } \\
\text { - Pyelonephritis } \\
\text { - Adenocarcinoma at anastomotic site }\end{array}$ \\
\hline
\end{tabular}

Table 2 Ideal characteristics of a urinary reservoir.

\begin{tabular}{ll}
\hline Characteristic & Comments \\
\hline Low-pressure system & $\begin{array}{c}\text { Higher internal pressure in the reservoir may overcome the } \\
\text { external sphincter mechanisms that maintain continence. }\end{array}$ \\
$\begin{array}{c}\text { Stores a functional amount of urine }(\approx 500 \mathrm{~mL}) \\
\text { Reliable, complete continence }\end{array}$ & $\begin{array}{l}\text { Detubularisation of intestinal } \\
\text { segments limits the ability to generate a peristaltic pressure } \\
\text { wave. These waves can contribute to incontinence. }\end{array}$ \\
$\begin{array}{c}\text { Complete voluntary control of voiding } \\
\text { No absorption of urinary waste products by } \\
\text { the reservoir walls }\end{array}$ & Minimises the likelihood of metabolic complications. \\
\hline
\end{tabular}


However, ureterosigmoidostomy is prone to detrimental upper tract changes in patients over time, e.g. $\geq 10$ years $[1,2]$. In addition, the mixture of faecal and urinary streams predisposed patients to a higher risk of bowel adenocarcinoma [3,4]. Several modifications of the ureterosigmoidostomy were developed to decrease the significant complication rate associated with the procedure. The sigma rectum, or Mainz II pouch, consists of a detubularised colon $6 \mathrm{~cm}$ both proximal and distal to the rectosigmoid junction, where the ureters are then implanted in a non-refluxing fashion [5]. The objective of this pouch was to create a low-pressure reservoir to protect the upper tracts, although the risk of adenocarcinoma still remained.

Kock et al. [6,7] descried the use of an intussuscepted nipple valve stabilised with permanent staples, whereupon the distal rectal segment is then opened and patched with ileum to lower reservoir pressure. This confines urine to a smaller, distal segment of bowel and therefore controls the amount of bowel to which the urine is exposed. The technique lowers the risk of metabolic complications but the risk of tumour formation remains [8]. The combination of these issues have led most practitioners to avoid ureterosigmoidostomy as a urinary diversion approach unless absolutely necessary.

\section{Conduits}

Conduits may be constructed using either colon or ileum. However, ileal conduits have become the 'gold standard' for incontinent diversion and indeed remain the procedure of choice for patients with contraindications to continent diversion. Ileal conduits are relatively easy and quick to create, minimising the rate of postoperative complications. Typically, the terminal $10-15 \mathrm{~cm}$ of ileum is preserved to maintain adequate absorption of bile salts, vitamin $\mathrm{B}_{12}$, and fat-soluble vitamins. The isolated segment of ileum used for diversion is exteriorised through the abdominal wall, where it serves as a passive conduit for urine to drain into an appliance. The presence of a stoma and external appliance can negatively affect a patient's body image. In patients with foreshortened mesentery, e.g. obese patients, a Turnbull loop stoma may be used [9].

\section{Continent Cutaneous Diversions}

Continent cutaneous reservoirs use a low-pressure pouch constructed of detubularised bowel with a functional mechanism designed to prevent involuntary efflux of urine flow. Reservoirs differ based upon the type of valve mechanism constructed, the type of catheterisable stoma created, and the exact segment of intestine used. As such, many technical variations exist, e.g. the Kock, Indiana, and Miami pouches. The most obvious advantage for this diversion lies in its continent nature, dispensing with the need for an external appliance. However, it requires clean intermittent self-catheterisation (CISC) through the stoma both to empty the reservoir and irrigate retained mucus. The ability of the patient to be technically able to catheterise the stoma over a lifetime cannot be overemphasised. Although these diversions have been largely supplanted by the orthotopic neobladder, they are still used when continence is desired in the setting of non-functional urethra or a positive intraoperative urethral margin obviating the ability to perform orthotopic diversion.

Results have varied in different institutions. Holmes et al. [10], for example, reported on 112 patients undergoing a modified Indiana pouch over a 14 -year period in a single institution series. In all, $90 \%$ of patients had complications, with incontinence representing the most common (28\%) complication. In all, 58\% of complications were related to the efferent loop of the pouch, including stomal stenosis in 15\% and difficulty with catheterisation in $10 \%$. Other problems included ureteroenteric anastomotic strictures (7\%), gallstones (26\%), kidney stones $(6 \%)$, stones within the pouch $(10 \%)$, and small bowel obstruction (5\%). In all, 26 (21\%) patients required an open operation, while $39(31.2 \%)$ required a minimally invasive operation for treatment of their complications.

Alternative pouch designs, particularly using the in situ appendix as the continence mechanism and catheterizable limb, have reported improved outcomes with a lower rate of major complications [11]. Reports using this mechanism or its modifications in previously irradiated patients suggest that improved outcomes can be achieved using appropriate design alterations $[12,13]$.

\section{Orthotopic Neobladders}

Orthotopic neobladders represent internal reservoirs connected to the native urethra that rely upon the external striated sphincter for continence. Reservoirs are typically constructed from detubularised small bowel and then anastomosed to the native urinary outflow tract.

Orthotopic neobladders were initially limited to men, as women were thought to have an increased risk of local recurrence and voiding dysfunction with orthotopic diversion. However, with experience and improved understanding of the female rhabdoid sphincteric mechanism, orthotopic diversion has become more common in women, becoming the procedure of choice for most patients after RC $[14,15]$.

However, appropriate patient selection is critical to the success of orthotopic diversions. It should not compromise the cancer control of a potentially curative surgery, and it is contraindicated if the urethra is non-functional or involved with tumour. Like continent cutaneous diversions, orthotopic neobladders require active patient participation to ensure proper maintenance of the reservoir. If medical or psychosocial issues preclude this level of cooperation, the patient may be better served by an incontinent ileal loop diversion. 
Table 3 Functional studies in men undergoing RC and orthotopic reconstruction.

\begin{tabular}{|c|c|c|c|c|c|c|}
\hline \multirow[t]{2}{*}{ Reference } & \multirow{2}{*}{$\begin{array}{l}\text { Number of } \\
\text { patients } \\
\text { (\% male) }\end{array}$} & \multirow{2}{*}{$\begin{array}{l}\text { Median } \\
\text { follow-up, } \\
\text { months }\end{array}$} & \multicolumn{3}{|c|}{ Continence rate } & \multirow{2}{*}{$\begin{array}{c}\text { CISC } \\
\text { needed (\%) }\end{array}$} \\
\hline & & & Day, \% & Night, \% & $\begin{array}{l}\text { Time of } \\
\text { assessment*, } \\
\text { years }\end{array}$ & \\
\hline Barre, P; 1996 [16] & $110(100)$ & 32 & 93 & 74 & NR & 1 \\
\hline Cancrini, A; 1996 [17] & $96(93)$ & 28 & 98 & 74 & 1 & NR \\
\hline Elmajian, D; 1996 [18] & $295(100)$ & 42 & 87 & 86 & 1 & 8 \\
\hline Hautmann et al. 1999 [19] & $363(100)$ & 57 & 96 & 95 & NR & 6 \\
\hline \multirow[t]{2}{*}{ Steven et al. $2000[20]$} & $166(100)$ & 32 & 98 & 80 & 3 & NR \\
\hline & & & 100 & 95 & 5 & NR \\
\hline Abol-Enein, H; 2001 [21] & $450(78)$ & 38 & 93 & 80 & NR & NR \\
\hline Madersbacher et al. 2002 [22] & $176(100)$ & 95 & 92 & 70 & 5 & NR \\
\hline Carrion, R; 2004 [23] & $138(82)$ & 41 & 91 & 70 & NR & 12 \\
\hline Sevin, G; 2004 [24] & $124(100)$ & NR & 92 & 90 & 4 & NR \\
\hline Stein, J; 2004 [25] & $209(81)$ & 33 & 87 & 72 & NR & $25^{\star *}$ \\
\hline Total number & $\begin{array}{l}2127 \\
(92 \%)\end{array}$ & & 93 & 83 & & \\
\hline
\end{tabular}

$N R$, not reported; ${ }^{*}$ Time point at which all patients were assessed after surgery; ${ }^{*} 20 \%$ of men and $43 \%$ of women.

\section{Role of Anti-reflux Mechanisms}

Some urinary diversions, e.g. the hemi-Kock pouch, use an anti-reflux mechanism to limit backflow of urine from the reservoir into the upper urinary tracts. Although this approximates the physiological anti-refluxing state of the native bladder and ureters, the need for anti-refluxing anastomoses in urinary diversions is controversial. Proponents cite the detrimental upper tract changes seen in patients $\geq 10$ years after creation of either freely refluxing ileal conduits or ureterosigmoidostomy $[1,2]$. However, it should be noted that reflux-associated complications with orthotopic neobladders have been predominantly seen in patients with highpressure reservoirs; contemporary neobladder designs use detubularised bowel segments configured to provide low filling pressures. In addition, some neobladder designs, e.g. the Studer reservoir, use a long isoperistaltic proximal limb, which provides resistance to retrograde flow and therefore additional anti-reflux protection [26]. Finally, non-refluxing anastomoses may be prone to a greater risk of complications, e.g. stricture, ischaemic fibrosis of the anti-reflux valve, or stone formation from staples used to construct the valve system. For example, in a randomised trial of 60 patients undergoing orthotopic neobladder diversion, construction of a non-refluxing anastomosis was associated with a higher incidence of anastomotic strictures (10\%) and secondary impairment of renal function compared with those with direct anastomoses [20].

\section{Functional Outcomes}

The functional goals of an orthotopic neobladder are to maintain day- and night-time continence and to allow consistent emptying of the neobladder without the need for CISC, while preserving renal function. Formal comparison of functional outcomes data is complicated by variability in the definition of continence, method of assessing continence, and timeframe of assessment relative to surgery.

In several large series comprised predominantly of men, dayand night-time continence rates ranged from 87 to $100 \%$, and 70 to $95 \%$, respectively (Table 3) [16-25]. In general, continence rates improve gradually postoperatively as the neobladder volume increases, with maximum control of voiding usually requiring several months. The Copenhagen group, for example, reported night-time continence rates of $75 \%$ at 1 year and $94 \%$ at 3 years, respectively, in a series of 166 patients [20]. Daytime continence also returns more rapidly than night-time continence $[19,22]$. The number of patients reporting simultaneous day- and night-time continence is lower, ranging from 12 to $58 \%$ (Table 4) [4,28-31].

Inadequate emptying of the neobladder in men is uncommon. The frequency and aetiology of this complication was illustrated in a single institution series of 655 men reported by Simon et al. [27]. Incomplete emptying, defined by a residual urine volume of $>100 \mathrm{~mL}$, was observed in 75 (11.5\%) cases. This was due to mechanical obstruction, i.e. benign strictures of the neovesicourethral anastomosis or local tumour recurrence, in $52(7.9 \%)$ patients. Of these, 14 patients required long-term catheterisation, while the remainder were able to resume complete bladder emptying after endoscopic management. Of the 23 (3.5\%) cases without a mechanical obstruction, failure of bladder emptying was due to dysfunctional voiding, requiring CISC or indwelling catheterisation.

Daytime continence rates range from 75 to $93 \%$ in women at average follow-ups of 20-33 months; night-time rates were also similar to men at $72-84 \%$ (Table 4 ) $[32,33]$. One significant difference seen in women has been the 
Table 4 Functional outcomes in women undergoing RC and orthotopic reconstruction.

\begin{tabular}{|c|c|c|c|c|c|}
\hline Reference & $\begin{array}{l}\text { Number } \\
\text { of women }\end{array}$ & $\begin{array}{l}\text { Median } \\
\text { follow-up, } \\
\text { months }\end{array}$ & $\begin{array}{l}\text { Continence } \\
\text { rate, } \% \\
\text { or } n / N\end{array}$ & $\begin{array}{c}\text { Catheterisation, } \\
\% \text { or } n / N\end{array}$ & $\begin{array}{l}\text { Continent during } \\
\text { day and night, } \\
\% \text { or } n / N\end{array}$ \\
\hline Ali-el-Dein, B; 2002 [4] & 60 & 20 & 93 & 84 & 14 \\
\hline Arai, Y; 1999 [28] & 12 & 33 & $10 / 12$ & $6 / 12$ & $4 / 12$ \\
\hline Hautmann, R; 2000 [29] & 42 & NR & $86^{*}$ & NR & 47 \\
\hline Stenzl, A; 2001 [30] & 102 & 24 & 82 & 72 & 12 \\
\hline Stein, J; 2002 [31] & 88 & 30 & $75-78^{\star * * *}$ & NR & $44-58^{\star *}$ \\
\hline
\end{tabular}

$N R$, not reported; ${ }^{*}$ Percentage of patients reporting continence both during the day and at night; ${ }^{* *}$ Range based on chart review and patient questionnaire.

Table 5 Issues affecting urinary diversion selection.

\begin{tabular}{llll}
\hline Concer control & \multicolumn{1}{c}{ General health } & Technical \\
\hline Risk of local recurrence & Functional status & Functioning urethra \\
Previous pelvic radiation & Previous surgeries & Tumour location & Compliance \\
Need for adjuvant therapy & Renal/hepatic function & Ability to catheterise & Sexual function \\
Secondary malignancies & Medical comorbidities & Mesentery length & Body image \\
Urethral or bladder neck involvement & Status of gastrointestinal tract & Bowel condition & Urinary function \\
& Body habitus & Operative duration & Family support \\
\hline
\end{tabular}

phenomenon of hypercontinence, leading to urinary retention. This is thought to be due in part to a posterior prolapse of the neobladder during Valsalva voiding. This has resulted in an increased need to perform CISC, ranging from 11 to $70 \%$. Techniques that have improved the anterior and posterior support of the neobladder have led to improved functional outcomes [34].

\section{HRQOL}

One of the primary reasons for selecting a continent diversion lies in the preservation of 'normal' body image. While some reports have noted improvements in various specific aspects of HRQOL, e.g. body image, with these reconstructive techniques, few formal studies have documented an improvement in overall HRQOL. In fact, most studies have failed to confirm superior outcomes in patients undergoing orthotopic as opposed to other forms of diversion. For example, the Vanderbilt group analysed RAND 36-Item Health Survey (SF-36) and Functional Assessment of Cancer Therapy-General (FACT-G) questionnaires from 29 patients with an ileal loop conduit compared with 42 with orthotopic neobladders [35]. Although there were advantages in HRQOL for those receiving an orthotopic neobladder, these patients were younger, and the differences could have been age-related. In addition, a systematic overview conducted by the University of California, Los Angeles (UCLA) group examined HRQOL after RC and urinary diversion for bladder cancer [36]. Of the 15 published studies, examined, none were randomised; only one of which was prospective in nature. The authors concluded that insufficient data were available to conclude that any one form of urinary diversion was associated with a better
HRQOL. The authors identified the lack of preoperative baseline assessment, the lack of longitudinal studies using valid and reliable measures, and the absence of a validated instrument to measure bladder cancer-specific HRQOL, as major limitations of currently published studies.

\section{Factors Influencing Choice of Procedure}

The primary goals in selecting a urinary diversion are to provide the lowest potential for complications and the highest HRQOL, while allowing for the timely completion of chemotherapy and therapeutic goals. The decision process is complex and involves consideration of issues related to cancer stage, patient comorbidities, treatment needs, and patient desires related to HRQOL (Table 5). While patient preference is important, absolute and relative contraindications for the use of various bowel segments and continent urinary reservoirs do exist (Table 6). Patients should be informed that intraoperative findings may dictate a change in the planned form of urinary diversion, e.g. positive urethral margin precluding orthotopic diversion. Even when an orthotopic neobladder is planned, all patients should have a stoma site marked preoperatively by an enterostomal therapist in the event that orthotopic diversion becomes unfeasible.

\section{Surgical and Oncological Considerations for the Lower Urinary Tract}

The primary goal of RC for bladder cancer is control of the underlying tumour, and effective resection must be the highest priority. Disease extent and anatomical considerations can therefore limit reconstructive options. 
Table 6 Absolute and relative contraindications for continent cutaneous/orthotopic neobladder urinary diversions.

\begin{tabular}{|c|c|}
\hline Absolute contraindications & Relative contraindications \\
\hline Impaired renal function & Associated comorbid conditions \\
\hline Impaired hepatic function & Advanced age \\
\hline $\begin{array}{l}\text { Physical or mental impairment } \\
\text { to perform CISC }\end{array}$ & Need for adjuvant chemotherapy \\
\hline $\begin{array}{l}\text { Positive apical urethral margin } \\
\text { (for neobladder) }\end{array}$ & Prior pelvic radiation \\
\hline \multirow[t]{3}{*}{ Unmotivated patient } & Bowel disease \\
\hline & Urethral pathology \\
\hline & $\begin{array}{l}\text { Extensive local disease with soft tissue } \\
\text { extension and high risk of local } \\
\text { recurrence }\end{array}$ \\
\hline
\end{tabular}

It is therefore critical to have an honest and informed discussion with patients preoperatively about the risks and benefits of all forms of urinary diversions in this context.

The reported incidence of urethral recurrence after $\mathrm{RC}$ ranges from 0 to $18 \%$, with a recent meta-analysis reporting an $8.1 \%$ overall incidence [37-40]. Most recurrences are detected $\leq 2$ years after RC, although late recurrences have been reported. Regular follow-up of the retained urethra is therefore recommended.

Several risk factors have been associated with urethral recurrence after RC, including multifocal disease, carcinoma in situ, upper tract urothelial carcinoma, and involvement of the bladder neck or prostatic urethra [41-43]. In men, one of the most important risk factors for urethral recurrence appears to be prostatic stromal invasion [37]. The University of Southern California group reported a 5 year probability of urethral recurrence of $6 \%$ for patients without prostatic involvement vs $15 \%$ for patients with superficial involvement vs $21 \%$ for those with stromal invasion of the prostate [44]. However, transurethral prostatic biopsy results do not always correlate with final pathology [45]. In addition, lower than expected urethral recurrence rates have been reported in patients who were orthotopically reconstructed despite involvement of the prostate. Thus, routine preoperative prostatic biopsies are no longer recommended and instead, intraoperative frozen sections of the distal urethral margin have been recommended before proceeding with an orthotopic neobladder $[46,47]$.

In women, bladder neck involvement is associated with a higher incidence of urethral recurrence and therefore represents an absolute contraindication to orthotopic diversion $[46,48,49]$. Nonetheless, $50 \%$ of woman with supposed bladder neck involvement have no pathological evidence of urethral involvement after urethrectomy. Some investigators have proposed using an intraoperative frozen section of the urethral margin to determine whether an orthotopic reconstruction is possible [47]. However, the decision to perform an orthotopic diversion in a female with tumour at the bladder neck should not be taken lightly, as urethral recurrence in a female is equivalent to a pelvic recurrence, leading eventually to death. Furthermore, some women will have periurethral gland involvement on final pathology despite negative urethral biopsies $[19,50]$.

The management of urethral recurrence after RC remains a total urethrectomy, including excision of the meatus. We follow patients with urinary cytology with either voided or urethral wash cytology depending on the diversion and cystoscope, and any patient with urethral-related symptoms, abnormal discharge, or haematuria.

Locally advanced bladder cancer and/or regional node-positive disease initially represented an absolute contraindication for a continent cutaneous or orthotopic urethral diversion for fear of difficulty in treating a local recurrence or giving chemoradiation with a urinary reservoir. Ileal conduits became the preferred diversion in this situation because of the potentially quicker recovery time and lower risk of perioperative complications. Nonetheless, continent diversions have been used successfully in carefully selected patients. Hautmann and Simon [50] reported on patients with locally advanced bladder cancer who underwent an orthotopic neobladder reconstruction, among which 17 (43\%) had concomitant distant metastases. In all, 36 (91\%) patients died from disease, three (8\%) from chemotherapy related complications and one (3\%) from unknown causes. In all, 40 (93\%) patients maintained satisfactory neobladder function until death. Local recurrence compromised the upper urinary tract, neobladder, and intestine in 24,10 , and seven cases, respectively, but removal of the neobladder was only required in one case due to enterovesicular fistula. Another treatment-related concern with continent diversion relates to chemotherapy. The start of adjuvant chemotherapy may be delayed due to the higher complication rate seen with continent diversions, although data are limited about the exact proportion of patients who experience delay [51]. In addition, the toxicity of chemotherapy can potentially be increased from the longer dwell time of urine in the reservoirs, although this has been addressed by the use of both increased hydration and the insertion of an indwelling catheter during active treatment infusion [52]. Overall, urinary diversion with neobladder construction can be considered in selected patients with regional metastases or locally advanced disease, as few such patients will probably have complications that disrupt neobladder function. However, short life-expectancy and/or an inability to perform CISC represent contraindications to orthotopic reconstruction [53].

An uncommon but important complication involves the possibility of secondary malignancy associated with the urinary diversion itself. Specifically, all urinary diversions using bowel, with or without separation of urine and faeces, may carry a higher risk for intestinal tumour development compared with the general population $[3,4,54]$. However, the median latency 
period is long at 10-13 years. Although the frequency of malignancy is higher after ureterosigmoidostomy than with an ileal conduit or continent diversion, long-term follow-up of large cohorts will be needed to estimate the incidence of such cancers with newer conduits and reservoirs $[55,56]$. Patients undergoing urinary diversion, particularly ureterosigmoidostomy should therefore undergo regular colonoscopic surveillance starting between 5 and 10 years after surgery [57-59].

\section{Other Considerations for The Upper Urinary Tract}

The upper urinary tract is also at risk of physiological deterioration in up to $60 \%$ of patients [60]. This occurs usually from infection, stones, lack of ureteric motility, or obstruction at the ureteroenteric anastomosis. This has resulted in $6 \%$ of patients with ileal conduits ultimately dying of renal failure, for example [61]. It is of note difficult to discriminate whether abnormal renal units that were present before urinary diversion caused the subsequent renal deterioration or whether the deterioration occurred due to the intrinsic abnormality for which the urinary diversion was created.

Patients with urinary diversions are also prone to bacteriuria and developing pyelonephritis [62]. Up to $17 \%$ of patients with conduits experience acute pyelonephritis, with a $4 \%$ death rate from sepsis. Interestingly, deterioration of the upper tracts appears more likely when urine cultures are positive for Proteus or Pseudomonas [63]. Up to 12\% of patients with urinary diversions are also at risk of developing renal calculi, due to hyperchloraemic metabolic acidosis, pre-existing pyelonephritis, and/or UTI with a urea-splitting organism $[62,64]$.

\section{Urinary Continence and/or Voiding Dysfunction \\ Continent Cutaneous Diversion}

The reported rates of incontinence for patients with continent cutaneous diversions vary significantly depending upon the criteria used to define incontinence and the differences in the duration of follow-up [10,33,65-67]. Day- and night-time continence rates with continent cutaneous reservoirs range from 90 to $98 \%[68,69]$.

The most frequent and troublesome long-term complication associated with continent cutaneous diversions involves the efferent limb and catheterizable stoma. The reported rate of stomal stenosis and difficulty in catheterising the stoma is $4-15 \%[10,67]$.

Incontinence with a continent cutaneous diversion can be due to uninhibited pouch contractions, poor pouch compliance, or an incompetent continence mechanism. Pouch urodynamics are helpful in categorising the cause of the incontinence. Patients with a poorly compliant, high-pressure reservoir may benefit from an initial trial of anticholinergics; refractory cases usually require reservoir augmentation to decrease pressure and increase capacity [70-72]. Incontinence secondary to incompetent continence mechanisms usually require open revision. Minimally invasive approaches, such as injecting bulking agents, can be helpful for appropriately selected, mild cases of incontinence.

\section{Orthotopic Neobladder}

The lack of uniformity in defining voiding dysfunction and incontinence, the often retrospective nature of assessment, and the lack of validated instruments for measurement in orthotopic neobladder series limit the ability to assess voiding dysfunction after orthotopic diversion. A recent meta-analysis of $>2000$ patients showed a $4-25 \%$ rate of CISC for incomplete emptying [32]. Daytime incontinence was present in $\approx 13 \%$ of patients. The rate of nocturnal incontinence is usually higher due to lack of the guarding reflex from loss of the native bladder and is in the range of $15-40 \%$.

A unique aspect of voiding dysfunction should be considered in women undergoing orthotopic reconstruction. Clinical experience has suggested that $16-25 \%$ of women choosing orthotopic reconstruction eventually experience urinary retention $[15,34,73,74]$. Possible mechanisms for this include mechanical kinking of the pouch at the posterior pouch-urethral junction. Herniation of the pouch wall through the prolapsed vaginal stump has also been proposed as a possible mechanism for retention [34]. Technical modifications, e.g. increased back-support of the pouch through omental packing behind the reservoir, suspension of the vaginal stump to the preserved round ligaments, and suspension of the reservoir dome to the back of the rectus abdominus muscles, have been proposed to reduce the incidence of urinary retention.

\section{Psychosocial and Medical Considerations}

Multiple factors need to be considered when choosing the appropriate procedure for an individual patient. In choosing the appropriate procedure, the patient and his family should have realistic expectations about the outcome associated with each reconstructive option. They should also understand the efforts that will be required on their part during the rehabilitation process. In addition, patients must have sufficient manual dexterity to master CISC, if the decision is made to proceed with a continent diversion. An enterostomal nurse specialist can be invaluable in educating the patient and family and assisting with the decision-making process [75].

Advanced age can complicate both the operative procedure and subsequent recovery [76]. Age has been associated with 
higher postoperative complication rates, but disease-specific survival rates are similar [77-79]. As such, elderly patients are usually offered primarily ileal conduits, whereas orthotopic neobladders tend to be reserved for younger, healthier patients $[80,81]$. Elderly patients need to also be counselled that the recovery of continence may take longer than in younger patients. For example, Madersbacher et al. [22] found that age is an important determinant of long-term reservoir capacity, nocturia, and continence status in patients with ileal neobladders. Similarly, Hautmann et al. [82] reported that continence status at the 5-year follow-up approached $100 \%$ in patients aged $<50$ years but only $90 \%$ for those aged $>60$ years. One of the explanations for this difference may be decreasing external urethral sphincter function with age or the decreased vigilance of elderly patients towards incontinence $[82,83]$. Nonetheless, experienced centres have reported continence rates of $>90 \%$ daytime and $>80 \%$ night-time continence in properly selected patients [84]. However, it should be noted that physiological age appears to be more relevant to patient outcome, and it is therefore recommended that no formal chronological age limit should be applied $[85,86]$. Rather, patient selection as determined by surgical fitness, motivation, and functional status is more appropriate. Our policy is to offer continent diversions to older patients if they are healthy and motivated enough to care for the diversion. If an older patient becomes incapacitated and unable to care for the continent diversion, then an indwelling Foley catheter may be placed into the diversion similar to what might be done for the native bladder.

Obesity can also increase the technical difficulty of RC and complicate orthotopic neobladder construction [87]. However, the postoperative management of an ileal loop conduit or a continent reservoir is also more difficult in the obese patient, and thus most surgeons therefore do not consider obesity to be a contraindication to reconstruction with an orthotopic neobladder [88]. Many, including the authors, feel that reconstruction to the urethra may be the least complicated reconstructive option for the obese patient. However, obesity may be associated with a higher incidence of a thickened foreshortened mesenteric root, which can increase the difficulty of bringing an orthotopic urinary diversion inferiorly to the native urethra.

Urologists should finally be aware that adequate renal function is required for the creation of any continent diversion. Continent diversion imposes an extra metabolic burden upon the kidneys, as urinary excretion products are resorbed through the mucosal surface. Typically, only mild metabolic abnormalities will be seen in patients who have normal renal function. However, for those patients with more severe renal dysfunction (serum creatinine values of $>2.0-2.5 \mathrm{mg} / \mathrm{dL}$ or $180-230 \mu \mathrm{M} / \mathrm{L}$ or estimated GFR of $<40 \mathrm{~mL} / \mathrm{min} / 1.73 \mathrm{~m}^{2}$ ), an ileal loop conduit is preferred over the continent alternatives.

\section{Complications \\ Surgery Related Complications}

Considerable variability exists in the reported early and long-term morbidity rates after urinary diversions. Morbidity rates $\leq 30$ days after surgery range between 20 and $56 \%$, while long-term morbidity $>30$ days ranges from 28 to $94 \%$ $[22,65,89]$. Diversion-related complications are specific to the type of diversion and are generally categorised into those involving the bowel anastomosis, those related to the type of reservoir/conduit, and those associated with the ureteroenteric anastomosis [33].

\section{Ileal conduits}

The ileal conduit is often chosen for patients with significant medical comorbidities in an effort to minimise postoperative complications. Because of the greater prevalence of risk factors in patients selected to undergo ileal conduit diversions, the rate of surgical complications still approaches that of continent diversions performed in healthier patients. None of the comparative studies control for the differences in comorbid status, and one can therefore assume that complication rates would be further increased if 'sicker' patients underwent continent diversion.

The overall rate of complications associated with conduits is similar for ileum and colon segments among properly selected patients $[22,60,95,96]$. The four most common complications reported are pyelonephritis in 5-23\%, ureteric obstruction in $2-22 \%$, urinary calculi in $3-16 \%$, and stomal complications in $2-62 \%$ of cases in a series of 412 patients with a median follow-up of 98 months $[22,60]$. The frequency of complications increased over time from $45 \%$ at 5 years to $94 \%$ at $>15$ years. The most frequent complications reported were renal insufficiency in $27 \%$, stomal problems in $24 \%$, bowel problems in $24 \%$, UTIs in $24 \%$, ureteric obstruction in $14 \%$, and urinary calculi in $9 \%$. The impact of these complications upon patients can be significant. Renal insufficiency leads to impaired clearance of drugs and medications. Complications, e.g. stomal stenosis, can exacerbate renal failure and require revision surgery. Small bowel obstruction may require conservative measures, such as nasogastric tube drainage, or more aggressive treatments, such as exploratory laparotomy and bowel resection. Ureteric obstruction may necessitate placement of stents or nephrostomy tubes, endoscopic treatment of strictures, or surgical revision of ureteroenteric anastomoses. The presence of urinary calculi may require lithotripsy and stent placement.

Continent cutaneous diversions and orthotopic neobladders

Continent urinary diversions involve multiple suture lines, valve mechanisms, tapered limbs, and longer operative times than ileal conduits. As such, they are subject to a higher incidence of urinary leaks in the early postoperative period 
Table 7 Comparison of complications in ileal conduits vs continent diversions.

\begin{tabular}{|c|c|c|c|c|}
\hline Type of diversion & Reference & No. of patients & Time from surgery, months & $\%$ Complications \\
\hline \multirow[t]{3}{*}{ Ileal conduit } & Parekh et al. 2000 [66] & 81 & 19 & 22 \\
\hline & Gburek et al. 1998 [90] & 66 & 20 & 18 \\
\hline & Madersbacher et al. 2003 [60] & 131 & 98 & 66 \\
\hline \multirow[t]{8}{*}{ Continent diversion } & Parekh et al. 2000 [66] & 117 & 20 & 12 \\
\hline & Gburek et al. 1998 [90] & 66 & 17 & 18 \\
\hline & Shimogaki et al. 1999 [91] & 8 & 59.9 & 0 \\
\hline & Mills et al. 2000 [92] & 15 & 19 & 13 \\
\hline & Ali-el-dein et al. 1999 [93] & 60 & 20.2 & 13 \\
\hline & Hautmann et al. 1999 [19] & 363 & 57 & $15.4-23.4^{*}$ \\
\hline & Steven et al. 2000 [20] & 166 & 32 & $23.5-37.4^{*}$ \\
\hline & Studer et al. 1997 [94] & 200 & $30-134$ & $12-22^{\star}$ \\
\hline
\end{tabular}

${ }^{*}$ Early ( $\leq 90$ days) vs late ( $>90$ days) complications.

Table 8 Early vs late complications in continent urinary diversions.

\begin{tabular}{|c|c|c|c|c|}
\hline Complication type & Early ( $\leq 30$ days) & $\%$ & Long ferm (30 days to death) & $\%$ \\
\hline \multirow[t]{4}{*}{ Reservoir-related } & Urinary leak & $1.8-10$ & & \\
\hline & Pyelonephritis & $0.9-13$ & Pyelonephritis & $3-10$ \\
\hline & & & Upper tract calculi & 3 \\
\hline & & & Pouch calculi & $5-35$ \\
\hline \multirow[t]{3}{*}{ Anastomosis-related } & Ureteric obstruction & $0-6.3$ & Ureteral obstruction/stricture & $2-30$ \\
\hline & Urethral or stomal stricture & $2-14.3$ & Renal deterioration & $0.4-10.5$ \\
\hline & & & Ureteric reflux & $<2$ \\
\hline \multirow[t]{2}{*}{ Bowel-related } & Faecal leak & $1-2$ & Metabolic abnormalities & $15-50$ \\
\hline & Prolonged ileus & $2-11$ & Bowel obstruction & $4-8$ \\
\hline \multirow[t]{5}{*}{ Other } & Wound infection & 5 & & \\
\hline & Wound dehiscence & 5 & Incisional hernia & $0-10$ \\
\hline & Deep venous thrombosis & $2-2.7$ & Deep venous thrombosis & $0-6.3$ \\
\hline & & & Loss of continence mechanism & $15-20$ \\
\hline & & & Hypercontinence (male vs female) & $3-9$ vs $10-50$ \\
\hline
\end{tabular}

and may be subject to pouch rupture at any time. Pouch rupture is treated initially with conservative measures, e.g. catheter drainage. If the urinary stream needs to be diverted further, nephrostomy tubes can be placed. If these measures still prove insufficient, surgical revision of the urinary diversion can then be performed.

The complications seen with continent urinary diversions differ in the early postoperative period compared with those seen in the long-term and are specific to the type of reservoir (Tables 7 and 8) $[10,19,20,33,60,65-67,90-94,96]$. If one combines the reported percentage of early and late complications in large institutional series associated with each procedure, the risk of having a significant complication over the lifetime of the patient is $18-36 \%$ for continent cutaneous reservoirs and $10-18 \%$ for orthotopic neobladders.

\section{Diminished Renal Function}

Compromise of renal function over time may be seen in patients after urinary diversion. The development of urinary tract obstruction at the site of anastomosis or reservoir/conduit outflow, stones, and chronic infection represent contributory factors. However, it is not clear whether the loss of renal function exceeds that expected in an ageing population, as kidney function also naturally gradually deteriorates in the elderly even in the absence of urinary tract surgery [52]. Careful surveillance for evidence of obstruction or stone formation will allow for prompt intervention and may prevent loss of renal function.

\section{Infection}

Infectious complications can contribute to acute morbidity and chronic renal insufficiency. Contributing factors include the use of intestinal segments normally colonised with bacteria, incomplete emptying leaving residual urine as a nidus for infection, and the use of CISC that introduces bacteria into the urinary reservoir. Although the presence of small bowel intestinal mucosa appears to promote asymptomatic bacterial colonisation, urosepsis rarely occurs unless the patient has recurrent UTIs. This was shown in a series of 66 patients with orthotopic neobladders reported by Wood et al. [97]. Asymptomatic bacteriuria was seen in $78 \%$ of the 55 patients who voided through an orthotopic neobladder, but only $39 \%$ of patients developed symptomatic urinary 
infection. Urosepsis rarely occurred, except in the context of recurrent UTIs. Thus, patients do not require chronic suppressive antibiotic therapy unless a history of recurrent UTIs exists. Those with acute infections should be treated with appropriate antimicrobial therapy for limited periods only.

\section{Nutritional and Metabolic Abnormalities}

Resection of an ileal or colonic segment of bowel may result in malabsorption of bile salts [98]. This can lead to lipid malabsorption and gallstone formation. However, the ileal segments used for urinary reconstruction are generally short enough to avoid this problem. For example, in one observational study of 114 patients without a history of symptomatic gallstone disease or previous cholecystectomy at the time of urinary diversion, $10 \%$ of men and $25 \%$ of women developed gallstones, an incidence consistent with that normally expected in the American population [99].

Resection of the ileum can also lead to inadequate absorption of the vitamin $B_{12}$ intrinsic factor complex. Vitamin $B_{12}$ deficiency may therefore ensue, manifested as either megaloblastic anaemia or with neurological symptoms. The incidence of vitamin $B_{12}$ deficiency after urinary diversion is unclear; long-term estimates range from zero to as high as $33 \%$ at 5 years after surgery $[19,20]$. This variability may be due to the different methods of testing for vitamin $B_{12}$ deficiency (e.g. the Schilling test, serum vitamin $B_{12}$ levels, methylmalonic acid and/or homocysteine levels, or overt megaloblastic anaemia), as well as differences related to the length and section of ileum used for the urinary diversion $[100,101]$. The authors recommend that vitamin $B_{12}$ levels be monitored annually beginning 3-5 years after diversion and that patients be evaluated for symptoms consistent with vitamin $B_{12}$ deficiency. Replacement therapy should be initiated as needed.

Electrolyte abnormalities may also result from the reabsorption of excreted metabolites. For example, ureterosigmoidostomy and diversions using the ileum and colon can result in severe hyperchloraemic hypokalaemic metabolic acidosis, although the severity of the acidosis is lessened in newer reconstructive procedures that limit the amount of time that urine is in contact with bowel mucosa [98]. For example, a contemporary series of 363 men with ileal neobladders reported by Hautmann et al. [19] reported only a $1 \%$ rate of severe metabolic acidosis, although nearly one-half of all patients required some form of alkalinizing treatment due to mild acidosis. Hyperchloraemic hypokalaemic metabolic acidosis is typically treated using sodium bicarbonate $\left(\mathrm{NaHCO}_{3}\right)$. In contrast, jejeunal diversions can result in hypochloraemic hypokalaemic metabolic acidosis, best treated using sodium chloride $(\mathrm{NaCl})$, chlorpromazine, or nicotinic acid. Regardless of the type of diversion created, regular monitoring of electrolytes with each follow-up visit will allow for the timely institution of appropriate corrective therapy as needed.

\section{Conclusions}

Urinary tract reconstruction after RC represents a complex process that attempts to maximise HRQOL for patients after surgery. In appropriately selected patients, the creation of an orthotopic neobladder permits the elimination of an external stoma and preservation of body image without compromising cancer control. However, the patient must be fully educated and committed to the labour-intensive rehabilitation process. He must also possess adequate manual dexterity to perform CISC when necessary. When involvement of the urinary outflow tract by tumour prevents the use of an orthotopic neobladder, a continent cutaneous reservoir may still offer substantial advantages in terms of preserving body image over an incontinent ileal conduit. For patients who are not candidates for either type of continent diversion, the ileal loop remains an acceptable and reliable option.

The choice of urinary diversion involves many different factors. It appears that HRQOL differences mainly stem from preservation of body image, particularly with orthotopic neobladders. More detailed analysis of HRQOL differences will require prospective studies with adequate baseline measures using validated instruments. It is important to note that each type of urinary diversion comes with potential complications, ranging from specific metabolic and nutritional abnormalities to infection, bowel obstruction, renal deterioration, and pouch rupture. One must always be vigilant for urethral recurrence in orthotopic reconstruction, which carries a poor prognosis for patients.

The ideal urinary diversion should successfully preserve renal function while managing urinary outflow and minimising morbidity to the patient. Much progress has been made in the field of urinary reconstruction since the introduction of ureterosigmoidostomy. Newer urinary diversions are able to decrease the risk of secondary malignancy, provide continence, and preserve body image to a much greater extent. However, the quest for further improving urinary diversion continues in an effort to benefit patients.

\section{Conflict of Interest}

None declared.

\section{References}

1 Studer UE, Danuser H, Thalmann GN, Springer JP, Turner WH. Antireflux nipples or afferent tubular segments in 70 patients with ileal low pressure bladder substitutes: long-term results of a prospective randomized trial. J Urol 1996; 156: 1913-7

2 Boxer RJ, Fritzsche P, Skinner DG et al. Replacement of the ureter by small intestine: clinical application and results of the ileal ureter in 89 patients. J Urol 1979; 121: 728-31 
3 Austen M, Kalble T. Secondary malignancies in different forms of urinary diversion using isolated gut. J Urol 2004; 172: 831-8

4 Ali-El-Dein B, El-Tabey N, Abdel-Latif M, Abdel-Rahim M, El-Bahnasawy MS. Late uro-ileal cancer after incorporation of ileum into the urinary tract. J Urol 2002; 167: 84-8

5 Stein R, Fisch M, Beetz R et al. Urinary diversion in children and young adults using the Mainz Pouch I technique. Br J Urol 1997; 79: 354-61

6 Koch MO, McDougal WS. Bone demineralization following ureterosigmoid anastomosis: an experimental study in rats. J Urol 1988; 140: 856-9

7 Kock NG, Ghoneim MA, Lycke KG, Mahran MR. Urinary diversion to the augmented and valved rectum: preliminary results with a novel surgical procedure. J Urol 1988; 140: 1375-9

8 Rink R, Retik A. Ureteroileocecal sigmoidostomy and avoidance of carcinoma of the colon. In King L, Stone A, Webster G eds, Bladder Reconstruction and Continent Urinary Diversion, St. Louis, MO: Mosby-Year Book, 1991: 221

9 Turnbull RB Jr. Intestinal stomas. Surg Clin North Am 1958; 38: 1361-72

10 Holmes DG, Thrasher JB, Park GY, Kueker DC, Weigel JW. Long-term complications related to the modified Indiana pouch. Urology 2002; 60: 603-6

11 Bochner BH, McCreath WA, Aubey JJ et al. Use of an ureteroileocecal appendicostomy urinary reservoir in patients with recurrent pelvic malignancies treated with radiation. Gynecol Oncol 2004; 94: 140-6

12 Mirhashemi R, Lamrbou N, Hus N, Salom E, Penalver MA, Averette HE. The gastrointestinal complications of the Miami Pouch: a review of 77 cases. Gynecol Oncol 2004; 92: 220-4

13 Angioli R, Estape R, Cantuaria G et al. Urinary complications of Miami pouch: trend of conservative management. Am J Obstet Gynecol 1998; 179: $343-8$

14 Gschwend JE. Bladder substitution. Curr Opin Urol 2003; 13: 477-82

15 Stenzl A, Holtl L. Orthotopic bladder reconstruction in women - what we have learned over the last decade. Crit Rev Oncol Hematol 2003; 47: $147-54$

16 Barre PH, Herve JM, Botto H, Camey M. Update on the Camey II procedure. World J Urol 1996; 14: 27-8

17 Cancrini A, De Carli P, Pompeo V et al. Lower urinary tract reconstruction following cystectomy: experience and results in 96 patients using the orthotopic ileal bladder substitution of Studer et al. Eur Urol 1996; 29: 204-9

18 Elmajian DA, Stein JP, Esrig D et al. The Kock ileal neobladder: updated experience in 295 male patients. J Urol 1996; 156: 920-5

19 Hautmann RE, de Petriconi R, Gottfried HW, Kleinschmidt K, Mattes R, Paiss T. The ileal neobladder: complications and functional results in 363 patients after 11 years of followup. J Urol 1999; 161: 422-8

20 Steven K, Poulsen AL. The orthotopic Kock ileal neobladder: functional results, urodynamic features, complications and survival in 166 men. J Urol 2000; 164: 288-95

21 Abol-Enein H, Ghoneim MA. Functional results of orthotopic ileal neobladder with serous-lined extramural ureteral reimplantation: experience with 450 patients. J Urol 2001; 165: 1427-32

22 Madersbacher S, Mohrle K, Burkhard F, Studer UE. Long-term voiding pattern of patients with ileal orthotopic bladder substitutes. J Urol 2002; 167: 2052-7

23 Carrion R, Arap S, Corcione G et al. A multi-institutional study of orthotopic neobladders: functional results in men and women. BJU Int 2004; 93: 803-6

24 Sevin G, Soyupek S, Armagan A, Hoscan MB, Oksay T. Ileal orthotopic neobladder (modified Hautmann) via a shorter detubularized ileal segment: experience and results. BJU Int 2004; 94: 355-9

25 Stein JP, Dunn MD, Quek ML, Miranda G, Skinner DG. The orthotopic T pouch ileal neobladder: experience with 209 patients. J Urol 2004; 172: $584-7$
26 Pantuck AJ, Han KR, Perrotti M, Weiss RE, Cummings KB. Ureteroenteric anastomosis in continent urinary diversion: long-term results and complications of direct versus nonrefluxing techniques. J Urol 2000; 163: 450-5

27 Simon J, Bartsch G Jr, Kufer R, Gschwend JE, Volkmer BG, Hautmann RE. Neobladder emptying failure in males: incidence, etiology and therapeutic options. J Urol 2006; 176: 1468-72

28 Arai Y, Okubo K, Konami T et al. Voiding function of orthotopic ileal neobladder in women. Urology 1999; 54: 44-9

29 Hautmann RE, de Petriconi R, Kleinschmidt K, Gottfried HW, Gschwend JE. Orthotopic ileal neobladder in females: impact of the urethral resection line on functional results. Int Urogynecol J Pelvic Floor Dysfunct 2000; 11: 224-9; discussion 30

30 Stenzl A, Jarolim L, Coloby P et al. Urethra-sparing cystectomy and orthotopic urinary diversion in women with malignant pelvic tumors. Cancer 2001; 92: 1864-71

31 Stein JP, Ginsberg DA, Skinner DG. Indications and technique of the orthotopic neobladder in women. Urol Clin North Am 2002; 29: 725-34, xi

32 Steers WD. Voiding dysfunction in the orthotopic neobladder. World J Urol 2000; 18: 330-7

33 Farnham SB, Cookson MS. Surgical complications of urinary diversion. World J Urol 2004; 22: 157-67

34 Ali-El-Dein B, Gomha M, Ghoneim MA. Critical evaluation of the problem of chronic urinary retention after orthotopic bladder substitution in women. J Urol 2002; 168: 587-92

35 Dutta SC, Chang SC, Coffey CS, Smith JA Jr, Jack G, Cookson MS. Health related quality of life assessment after radical cystectomy: comparison of ileal conduit with continent orthotopic neobladder. J Urol 2002; 168: 164-7

36 Porter MP, Penson DF. Health related quality of life after radical cystectomy and urinary diversion for bladder cancer: a systematic review and critical analysis of the literature. J Urol 2005; 173: 1318-22

37 Freeman JA, Tarter TA, Esrig D et al. Urethral recurrence in patients with orthotopic ileal neobladders. J Urol 1996; 156: 1615-9

38 Levinson AK, Johnson DE, Wishnow KI. Indications for urethrectomy in an era of continent urinary diversion. J Urol 1990; 144: 73-5

39 Tobisu K, Tanaka Y, Mizutani T, Kakizoe T. Transitional cell carcinoma of the urethra in men following cystectomy for bladder cancer: multivariate analysis for risk factors. J Urol 1991; 146: 1551-4

40 Schellhammer PF, Whitmore WF Jr. Transitional cell carcinoma of the urethra in men having cystectomy for bladder cancer. J Urol 1976; 115: $56-60$

41 Herr HW, Donat SM, Bajorin DF. Post-chemotherapy surgery in patients with unresectable or regionally metastatic bladder cancer. J Urol 2001; 165: 811-4

42 Donat SM, Wei DC, McGuire MS, Herr HW. The efficacy of transurethral biopsy for predicting the long-term clinical impact of prostatic invasive bladder cancer. J Urol 2001; 165: 1580-4

43 Donat SM, Genega EM, Herr HW, Reuter VE. Mechanisms of prostatic stromal invasion in patients with bladder cancer: clinical significance. J Urol 2001; 165: 1117-20

44 Hardeman SW, Soloway MS. Urethral recurrence following radical cystectomy. J Urol 1990; 144: 666-9

45 Lebret T, Herve JM, Barre P et al. Urethral recurrence of transitional cell carcinoma of the bladder. Predictive value of preoperative latero-montanal biopsies and urethral frozen sections during prostatocystectomy. Eur Urol 1998; 33: 170-4

46 Stein JP, Esrig D, Freeman JA et al. Prospective pathologic analysis of female cystectomy specimens: risk factors for orthotopic diversion in women. Urology 1998; 51: 951-5 
47 Maralani S, Wood DP Jr, Grignon D, Banerjee M, Sakr W, Pontes JE. Incidence of urethral involvement in female bladder cancer: an anatomic pathologic study. Urology 1997; 50: 537-41

48 Ali-el-Dein B, Abdel-Latif M, Ashamallah A, Abdel-Rahim M, Ghoneim M. Local urethral recurrence after radical cystectomy and orthotopic bladder substitution in women: a prospective study. J Urol 2004; 171 : 275-8

49 Stenzl A, Bartsch G, Rogatsch H. The remnant urothelium after reconstructive bladder surgery. Eur Urol 2002; 41: 124-31

50 Hautmann RE, Simon J. Ileal neobladder and local recurrence of bladder cancer: patterns of failure and impact on function in men. J Urol 1999; 162: 1963-6

51 Srinivas S, Mahalati K, Freiha FS. Methotrexate tolerance in patients with ileal conduits and continent diversions. Cancer 1998; 82: 1134-6

52 Hautmann RE. Urinary diversion: ileal conduit to neobladder. J Urol 2003; 169: 834-42

53 North AC, Lakshmanan Y. Malignancy associated with the use of intestinal segments in the urinary tract. Urol Oncol 2007; 25: 165-7

54 Spence HM, Hoffman WW, Fosmire GP. Tumour of the colon as a late complication of ureterosigmoidostomy for exstrophy of the bladder. $\mathrm{Br} \mathrm{J}$ Urol 1979; 51: 466-70

55 Azimuddin K, Khubchandani IT, Stasik JJ, Rosen L, Riether RD. Neoplasia after ureterosigmoidostomy. Dis Colon Rectum 1999; 42: $1632-8$

56 Fichtner J. Follow-up after urinary diversion. Urol Int 1999; 63: 40-5

57 Woodhouse CR. Guidelines for monitoring of patients with ureterosigmoidostomy. Gut 2002; 51 (Suppl. 5): V15-6

58 Khan MN, Naqvi AH, Lee RE. Carcinoma of sigmoid colon following urinary diversion: a case report and review of literature. World J Surg Oncol 2004; 2: 20

59 Hurlstone DP, Wells JM, Bhala N, McAlindon ME. Ureterosigmoid anastomosis: risk of colorectal cancer and implications for colonoscopists. Gastrointest Endosc 2004; 59: 248-54

60 Madersbacher S, Schmidt J, Eberle JM et al. Long-term outcome of ileal conduit diversion. J Urol 2003; 169: 985-90

61 Richie JP. Intestinal loop urinary diversion in children. J Urol 1974; 111 : $687-9$

62 Schmidt JD, Hawtrey CE, Flocks RH, Culp DA. Complications, results and problems of ileal conduit diversions. J Urol 1973; 109: 210-6

63 McDougal WS. Bladder reconstruction following cystectomy by uretero-ileo-colourethrostomy. J Urol 1986; 135: 698-701

64 Dretler SP. The pathogenesis of urinary tract calculi occurring after ileal conduit diversion. I. Clinical study. II. Conduit study. 3. Prevention. J Urol 1973; 109: 204-9

65 Killeen KP, Libertino JA. Management of bowel and urinary tract complications after urinary diversion. Urol Clin North Am 1988; 15 : 183-94

66 Parekh DJ, Gilbert WB, Koch MO, Smith JA Jr. Continent urinary reconstruction versus ileal conduit: a contemporary single-institution comparison of perioperative morbidity and mortality. Urology 2000; 55: 852-5

67 Webster C, Bukkapatnam R, Seigne JD et al. Continent colonic urinary reservoir (Florida pouch): long-term surgical complications (greater than 11 years). J Urol 2003; 169: 174-6

68 Sumfest JM, Burns MW, Mitchell ME. The Mitrofanoff principle in urinary reconstruction. J Urol 1993; 150: 1875-7

69 Bihrle R. The Indiana pouch continent urinary reservoir. Urol Clin North Am 1997; 24: 773-9

70 Sheldon CA, Reeves D, Lewis AG. Oxybutynin administration diminishes the high gastric muscular tone associated with bladder reconstruction. J Urol 1995; 153: 461-2

71 El-Bahnasawy MS, Shaaban H, Gomha MA, Nabeeh A. Clinical and urodynamic efficacy of oxybutynin and verapamil in the treatment of nocturnal enuresis after formation of orthotopic ileal neobladders. A prospective, randomized, crossover study. Scand J Urol Nephrol 2008; 42: 344-51

72 Christmas TJ, Smith GL, Rickards D. Diagnosis and management of high-pressure peristaltic contractions in cystoplasties. Br J Urol 1997; 79: 879-82

73 Lee CT, Hafez KS, Sheffield JH, Joshi DP, Montie JE. Orthotopic bladder substitution in women: nontraditional applications. J Urol 2004; 171 : $1585-8$

74 Stein JP, Grossfeld GD, Freeman JA et al. Orthotopic lower urinary tract reconstruction in women using the Kock ileal neobladder: updated experience in 34 patients. J Urol 1997; 158: 400-5

75 van Savage JG, Slaughenhoupt BL. Approach to urinary diversion in the surgical patient. J Surg Oncol 2000; 73: 33-8

76 Aghazadeh MA, Barocas DA, Salem S et al. Determining factors for hospital discharge status after radical cystectomy in a large contemporary cohort. J Urol 2010; 185: 85-9

77 Lughezzani G, Sun M, Shariat SF et al. A population-based competing-risks analysis of the survival of patients treated with radical cystectomy for bladder cancer. Cancer 2011; 117: 103-9

78 Donat SM, Siegrist T, Cronin A, Savage C, Milowsky MI, Herr HW. Radical cystectomy in octogenarians - does morbidity outweigh the potential survival benefits? J Urol 2010; 183: 2171-7

79 Koppie TM, Serio AM, Vickers AJ et al. Age-adjusted Charlson comorbidity score is associated with treatment decisions and clinical outcomes for patients undergoing radical cystectomy for bladder cancer. Cancer 2008; 112: 2384-92

80 Stein JP, Lieskovsky G, Cote R et al. Radical cystectomy in the treatment of invasive bladder cancer: long-term results in 1054 patients. J Clin Oncol 2001; 19: 666-75

81 Madersbacher S, Hochreiter W, Burkhard F et al. Radical cystectomy for bladder cancer today - a homogeneous series without neoadjuvant therapy. J Clin Oncol 2003; 21: 690-6

82 Hautmann RE, Miller K, Steiner U, Wenderoth U. The ileal neobladder: 6 years of experience with more than 200 patients. J Urol 1993; 150: $40-5$

83 Hugonnet CL, Danuser H, Springer JP, Studer UE. Decreased sensitivity in the membranous urethra after orthotopic ileal bladder substitute. J Urol 1999; 161: 418-21

84 Kessler TM, Burkhard FC, Perimenis P et al. Attempted nerve sparing surgery and age have a significant effect on urinary continence and erectile function after radical cystoprostatectomy and ileal orthotopic bladder substitution. J Urol 2004; 172: 1323-7

85 Sogni F, Brausi M, Frea B et al. Morbidity and quality of life in elderly patients receiving ileal conduit or orthotopic neobladder after radical cystectomy for invasive bladder cancer. Urology 2008; 71: 919-23

86 Clark PE, Stein JP, Groshen SG et al. Radical cystectomy in the elderly: comparison of clincal outcomes between younger and older patients. Cancer 2005; 104: 36-43

87 Lee CT, Dunn RL, Chen BT, Joshi DP, Sheffield J, Montie JE. Impact of body mass index on radical cystectomy. J Urol 2004; 172: 1281-5

88 Reyes MA, Nieder AM, Kava BR, Soloway MS, Manoharan M. Does body mass index affect outcome after reconstruction of orthotopic neobladder? Urology 2007; 69: 475-8

89 Perimenis P, Burkhard FC, Kessler TM, Gramann T, Studer UE. Ileal orthotopic bladder substitute combined with an afferent tubular segment: long-term upper urinary tract changes and voiding pattern. Eur Urol 2004; 46: 604-9

90 Gburek BM, Lieber MM, Blute ML. Comparison of studer ileal neobladder and ileal conduit urinary diversion with respect to perioperative outcome and late complications. J Urol 1998; 160: $721-3$ 
91 Shimogaki H, Okada H, Fujisawa $M$ et al. Long-term experience with orthotopic reconstruction of the lower urinary tract in women. J Urol 1999; 161: 573-7

92 Mills RD, Studer UE. Female orthotopic bladder substitution: a good operation in the right circumstances. J Urol 2000; 163: 1501-4

93 Ali-el-Dein B, el-Sobky E, Hohenfellner M, Ghoneim MA. Orthotopic bladder substitution in women: functional evaluation. J Urol 1999; 161: 1875-80

94 Studer UE, Zingg EJ. Ileal orthotopic bladder substitutes. What we have learned from 12 years' experience with 200 patients. Urol Clin North Am 1997; 24: 781-93

95 Morales P, Golimbu M. Colonic urinary diversion: 10 years of experience. J Urol 1975; 113: 302-7

96 Jahnson S, Pedersen J. Cystectomy and urinary diversion during twenty years - complications and metabolic implications. Eur Urol 1993; 24: 343-9

97 Wood DP Jr, Bianco FJ Jr, Pontes JE, Heath MA, DaJusta D. Incidence and significance of positive urine cultures in patients with an orthotopic neobladder. J Urol 2003; 169: 2196-9

98 Mills RD, Studer UE. Metabolic consequences of continent urinary diversion. J Urol 1999; 161: 1057-66
99 Holmes DG, Park GY, Thrasher JB, Kueker D, Weigel JW. Incidence of cholelithiasis in 125 continent urinary diversions. J Urol 2001; 165: 1897-9

100 Fujisawa M, Gotoh A, Nakamura I et al. Long-term assessment of serum vitamin $\mathrm{B}(12)$ concentrations in patients with various types of orthotopic intestinal neobladder. Urology 2000; 56: 236-40

101 Ganesan T, Khadra MH, Wallis J, Neal DE. Vitamin B12 malabsorption following bladder reconstruction or diversion with bowel segments. ANZ J Surg 2002; 72: 479-82

Correspondence: Shahrokh F. Shariat, James Buchanan Brady Foundation, Department of Urology, Weill Medical College of Cornell University, 525 E. 68th St., Starr 900, New York, NY 10065, USA.

e-mail: sfs2002@med.cornell.edu

Abbreviations: CISC, clean intermittent self-catheterisation; HRQOL, health-related quality of life; RC, radical cystectomy; UCLA, University of California, Los Angeles. 